\title{
Change of photochemical oxidant concentration by increase of VOCs emission from vegetations due to global warming
}

\author{
A. Kondo, A. Kaga, Y. Shimoda, Y. Inoue, D. Narumi, H. Bao, \\ T. Machimura, M. Tada \& K. Sakaguchi \\ Graduate School of Engineering Osaka University, Osaka, Japan
}

\begin{abstract}
VOCs emission experiments were conducted in a growth chamber in which temperature and luminous intensity can be controlled. Temperature was set at the typical summer temperature in Osaka and luminous intensity was set at $1000\left(\mu \mathrm{mol} / \mathrm{m}^{2} / \mathrm{s}\right)$ during daytime. The standard VOCs emissions from four representative Japanese plant species (Cryptomeria japonica, Chamaecyparis obtuse, Pinus densiflora and Quercus serrata) and rice plants were measured. The species distributions and their leaf biomass densities in the Kinki district were determined by the forest database and the use of a geophysical information system. Consequently, the detail emission distributions of isoprene and monoterpenes were estimated. Photochemical oxidant concentration was simulated by considering VOCs emissions from forests and paddy fields that changed with temperature and luminous intensity. The simulated results of NO, $\mathrm{NO}_{2}$ and $\mathrm{O}_{3}$ reasonably agreed with the observed data at 12 monitoring locations. The numerical experiment of temperature increment by $1^{\circ} \mathrm{C}$ that causes both the increment of VOCs and the promotion of photochemical reaction, could represent the recent increase of oxidant concentration by global warming.

Keywords: photochemical oxidant, isoprene, monoterpenes, growth chamber experiment, numerical simulation.
\end{abstract}

\section{Introduction}

It is well known that reactive volatile organic compounds (VOCs) are emitted from vegetation, including urban landscapes, agricultural crops and forests. It is important to investigate VOCs emission amount and lots of inventories of VOCs 
emission have already been developed in several places (Parra [1] for Catalonia (Spain), Velasco [2] for the valley of Mexico, Wang [3] for Beijing (China) Xu [4]). Photochemical oxidant is generated by the photochemical reaction of $\mathrm{NO}_{\mathrm{x}}$ and VOCs, and its concentration rises by the increase of VOCs emission amount. It is reported that the average temperature goes up by 2-3 degrees by global warming and there is a possibility that this temperature raise may also make VOCs emission amount to increase, and may contribute to photochemical oxidant concentration increase. Therefore it is essential to accurately estimate VOCs emission from plant species. Among many VOCs, isoprene and monoterpene are mostly emitted VOCs by plant species in the world (Guenther [5]). Isoprene also is the dominant VOCs which is emitted by deciduous forests (Geron [6]). Therefore we measured isoprene and the total of nine kinds of monoterpen ( $\alpha$-pinen, $\beta$-pinene, myrcen, $\alpha$-phellandrene, $\alpha$-terpinene, $p$-cymene, limonene, $\gamma$-terpinene, terpinolene) from five plant species (Cryptomeria japonica, Chamaecyparis obtuse, Pinus densiflora Quercus serrata, and Rice plant). Moreover, we estimated the above VOCs emission distributions in the Kinki district by the forest database and the use of geophysical information system and simulated air pollution concentrations of $\mathrm{NO}, \mathrm{NO}_{2}$ and $\mathrm{O}_{3}$ by using them.

\section{Experiment of VOCs emission from trees}

\subsection{Method of growth chamber experiment}

In order to estimate the VOCs emission amount accurately in Japan, it is essential to conduct an experiment on predominant Japanese trees. Cryptomeria japonica, Chamaecyparis obtuse, Pinus densiflora and Quercus serrata were selected because a large percentage of the Kinki district is occupied by these species. The plants under investigation were 3-5 years old saplings planted in $10 \mathrm{~L}$ plastic pots. They were grown outside in the open air and regularly watered and fertilized during the growing season to provide optimal growth conditions. Since the area covered by paddy field is also predominantly large in the Kinki district, the VOCs emission from Rice plant was also measured. Sapling of Rice plant was planted in 10L plastic pots in spring and regularly measured till autumn. Five plants of each species were individually transferred $24 \mathrm{~h}$ ago the experiments to an $8800 \mathrm{~L}$ closed growth chamber. Attention was focused on minimizing physical damage to the plants. Plants were then adapted to the following experimental conditions: average temperature in Osaka and constant photosynthetic photon flux density $\left(1000 \mu \mathrm{mol} \mathrm{m} \mathrm{m}^{-2} \mathrm{~s}^{-1}\right)$. Gas samples of 1L were taken from the outlet of the chamber and collected at a flow rate of $100 \mathrm{ml} \mathrm{min}^{-1}$ onto carbonaceous traps packed in glass tubes (Perkin Elmer CAT. No. 25086). The airflow rates were controlled with a mass-flow controller. The trapped compounds were thermo desorbed at $205^{\circ} \mathrm{C}$ by using Automated Thermal Turbomatrix Desorber (Perkin Elmer ATD-50) and ten kinds of VOCs (isoprene, $\alpha$-pinen, $\beta$-pinene, myrcen, $\alpha$-phellandrene, $\alpha$-terpinene, p-cymene, limonene, $\gamma$ terpinene, terpinolene) were analysed by GC/MS (Shimazu GC-2010). 


\subsection{VOCs emission at standard condition}

There are two kinds of losses of VOCs in the growth chamber. Since the growth chamber cannot be perfectly closed, VOCs can leak slowly and constantly from the growth chamber. For evaluating the amount of this leak, we assumed the $\mathrm{CO}_{2}$ leak from the growth chamber as being equivalent to the VOCs leak. Thus the amount of VOCs leak was determined from the observed leaked amount of the $\mathrm{CO}_{2}$ from the growth chamber at the experimental conditions. The next kind of VOCs loss is the decomposition of VOCs by the photochemical reactions triggered by the artificial light in the growth chamber. To evaluate this decomposition loss of VOCs, we conducted experiments at various temperatures and luminous intensities to determine the decomposition rate of VOCs in the growth chamber. In this experiment, $10 \mu \mathrm{L}$ of ten kinds of VOCs were individually allowed to decompose in the growth chamber and the concentration of each VOC was noted for 6 hours at 30 minutes interval. In order to assess the biomass of the enclosed plants, the dry weight of individual leaves was determined after drying the plant materials for $48 \mathrm{~h}$ at $105 \mathrm{C}^{\circ}$. The results of VOCs emission experiment from trees after the compensation are shown in Table 1. Isoprene is emitted only from Quercus serrata, which is original deciduous broadleaf tree in Japan. A large amount of $\alpha$-pinene was detected from Cryptomeria japonica, Chamaecyparis obtusa and Pinus densiflora. There were few reports that Rice plant emits VOCs, but five kinds of monoterpens were detected.

Table 1: VOCs emission $(\mu \mathrm{g} / \mathrm{gdw} / \mathrm{h})$ from trees at standard condition $\left(30^{\circ} \mathrm{C}, \mathrm{PAR}=1000\left(\mu / \mathrm{mol} / \mathrm{m}^{2} / \mathrm{s}\right)\right)$.

\begin{tabular}{lccccc}
\hline Compound & \multicolumn{5}{c}{ VOCs emission $(\mu \mathrm{g} / \mathrm{gdw} / \mathrm{h})$} \\
\cline { 2 - 6 } & $\begin{array}{c}\text { Quercus } \\
\text { serrata }\end{array}$ & $\begin{array}{l}\text { Cryptomeria } \\
\text { japonica }\end{array}$ & $\begin{array}{l}\text { Chamaecyparis } \\
\text { obtusa }\end{array}$ & $\begin{array}{l}\text { Pinus } \\
\text { densiflora }\end{array}$ & $\begin{array}{l}\text { Rice } \\
\text { plant }\end{array}$ \\
\cline { 2 - 6 } -pinen & - & 1.30 & 1.89 & 5.33 & 0.24 \\
Myrcen & - & 0.06 & 1.89 & 5.33 & 0.02 \\
a-phellandrene & - & 0.32 & 0.22 & 0.84 & 0.03 \\
$\alpha$-terpinene & - & 0.20 & 0.35 & 1.79 & - \\
, p-cymene & - & 0.15 & 0.13 & 0.87 & - \\
, limonene & - & 0.10 & 0.13 & 0.23 & 0.03 \\
$\gamma$-terpinene & - & 0.40 & 0.28 & 0.14 & 0.08 \\
Terpinolene & - & 0.21 & - & 0.82 & - \\
\hline Isoprene & - & 0.08 & 0.49 & 0.27 & - \\
\hline
\end{tabular}

In the present investigation, we have undertaken an evaluation of the emissions of isoprene and monoterpene from the foliage forests over the Kinki district. By using the forest database which was created by GIS and the standard VOCs emission obtained from the experiment, VOCs emission maps were made. As a first step, the amount of tree $\left(\mathrm{m}^{3} / \mathrm{ha}\right)$ given by the forest database was converted to the weigh of tree $(\mathrm{kg} / \mathrm{ha})$ by using the tree density. After getting the data of tree weight, the weight of leaf was calculated by 


$$
W_{L}=a W_{T}^{b}
$$

where $W_{L}$ and $W_{T}$ are weight of leaf and weight of tree, respectively. $a$ and $b$ are the experimental constants and are shown in Table 2 with tree density.

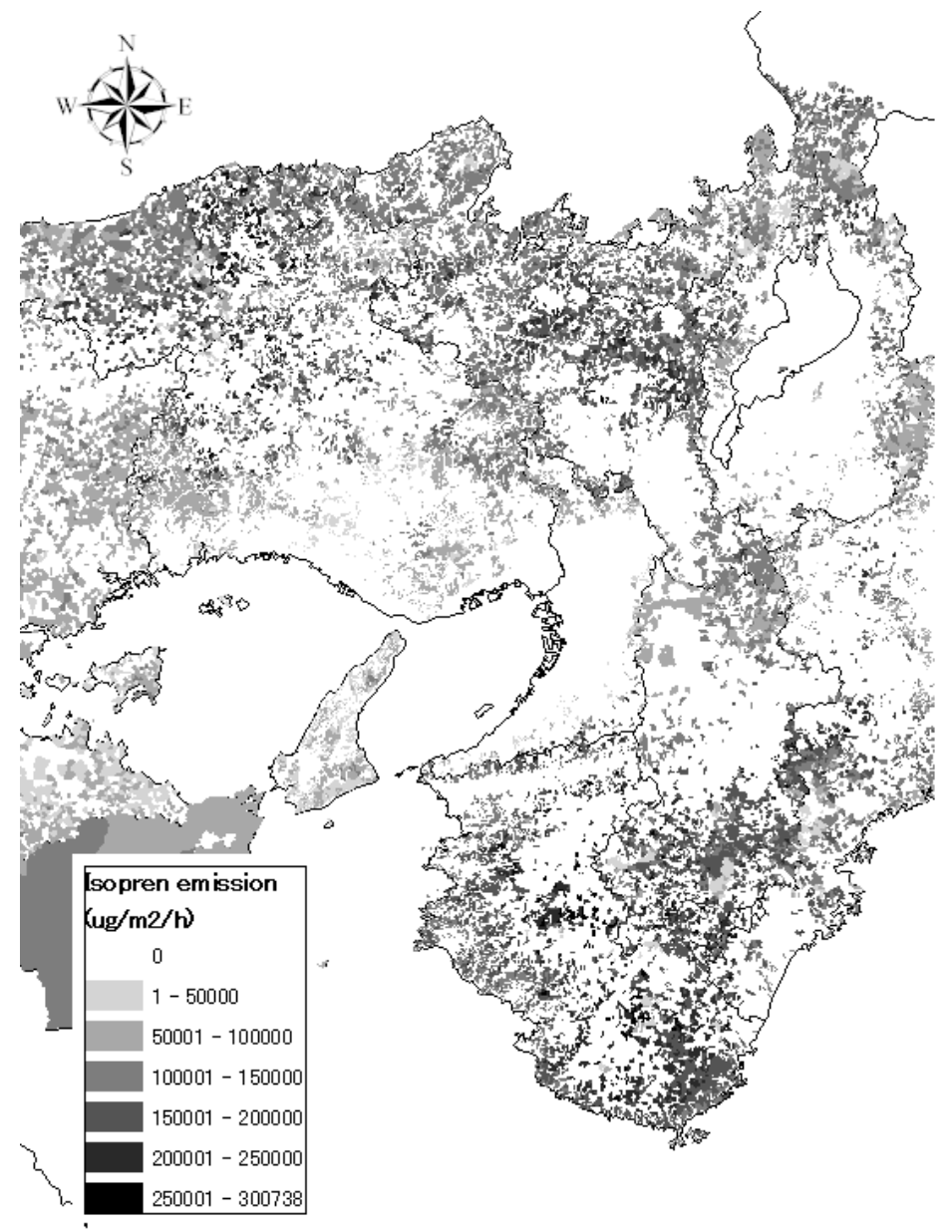

Figure 1: Emission map of isoprene.

Fig.1 and Fig.2 show the potential emission amount of isoprene and monoterpene from trees. The potential emission amount of isoprene and monoterpene are $1627[$ ton $/ \mathrm{h}]$ and $54.1[\mathrm{ton} / \mathrm{h}]$, respectively.

Fig. 3 shows the potential emission amount of monoterpene from Rice plant. The potential emission amount of monoterpene from Rice plant is around one twentieth of that from tree. However there are large areas of paddy fields in southeast Asia including Japan. As the monoterpene emission from rice plant strongly affects oxidant concentration, that its estimation is important. 


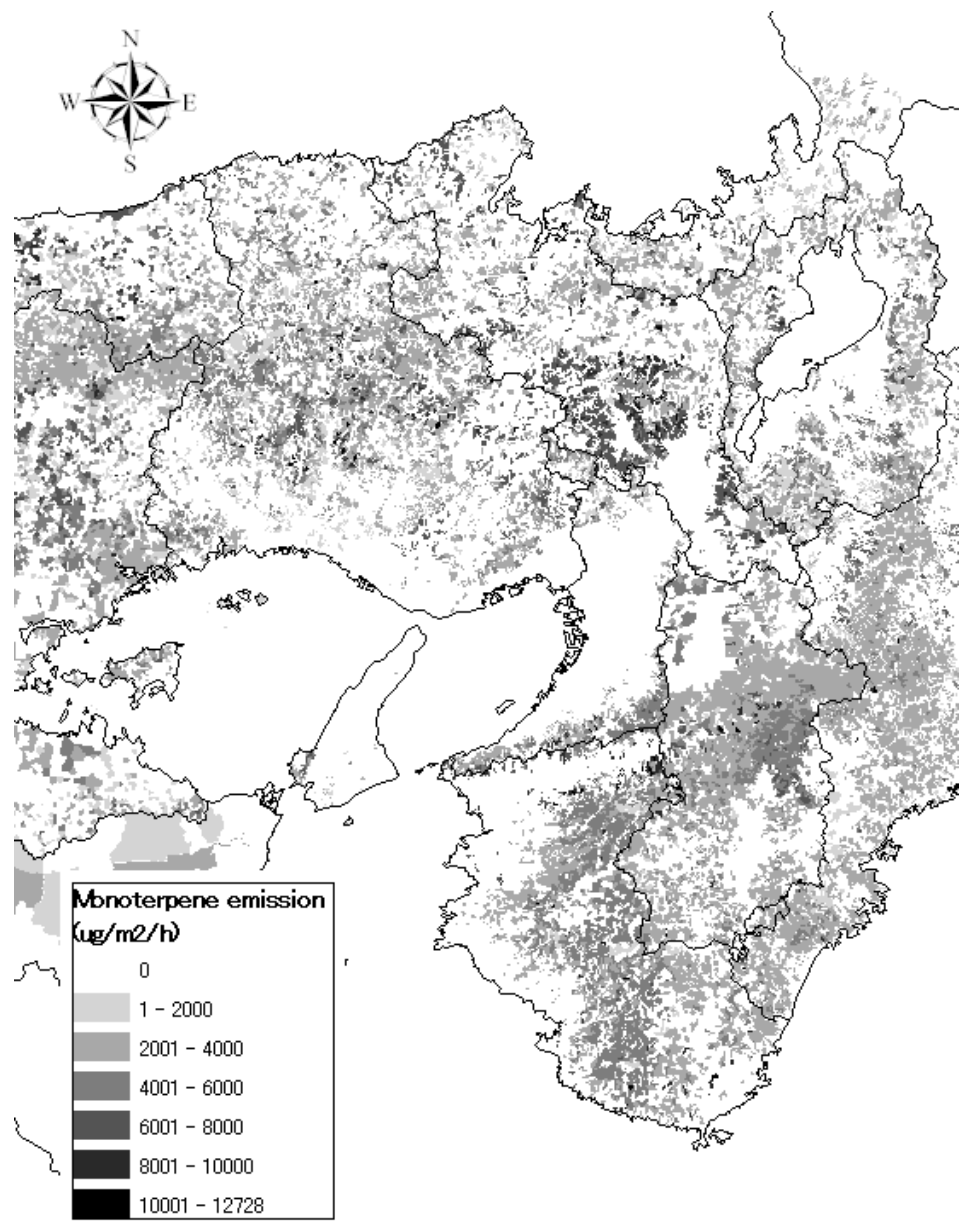

Figure 2: $\quad$ Emission map of monoterpene from tree.

Table 2: $\quad$ Experimental constants of each tree.

\begin{tabular}{lccc}
\hline & $a$ & $b$ & Tree density \\
\hline Quercus serrata & 0.323 & 0.730 & 0.35 \\
Cryptomeria japonica & 0.734 & 0.505 & 0.40 \\
Chamaecyparis obtusa & 0.492 & 0.502 & 0.47 \\
Pinus densiflora & 0.120 & 0.878 & 0.60 \\
\hline
\end{tabular}

\subsection{Dependency of temperature and PAR}

Guenther [5] have developed algorithmic expressions allowing a quantification of VOCs emissions from foliar biomass of forest ecosystems and other types of vegetation. Hourly isoprene emission $E_{\text {iso }}$ were given by 


$$
E_{\text {iso }}=E F_{\text {iso }} C^{i} C_{L} F B D
$$

where $F B D$ is the foliar biomass density $\left(\mathrm{g} / \mathrm{m}^{2}\right)$ and $E F_{\text {iso }}$ are the standard isoprene emission factors. $C_{T}^{i}$ and $C_{L}$ are the correction factor owing to temperature and PAR, respectively. These factors are defined by Eqs. (3) and (4), respectively.

$$
C^{i}{ }_{T}=\frac{\exp \frac{C_{T 1} \cdot\left(T-T_{s}\right)}{R \cdot T \cdot T_{s}}}{1+\exp \frac{C_{T 2} \cdot\left(T-T_{m}\right)}{R \cdot T_{s} \cdot T}}
$$

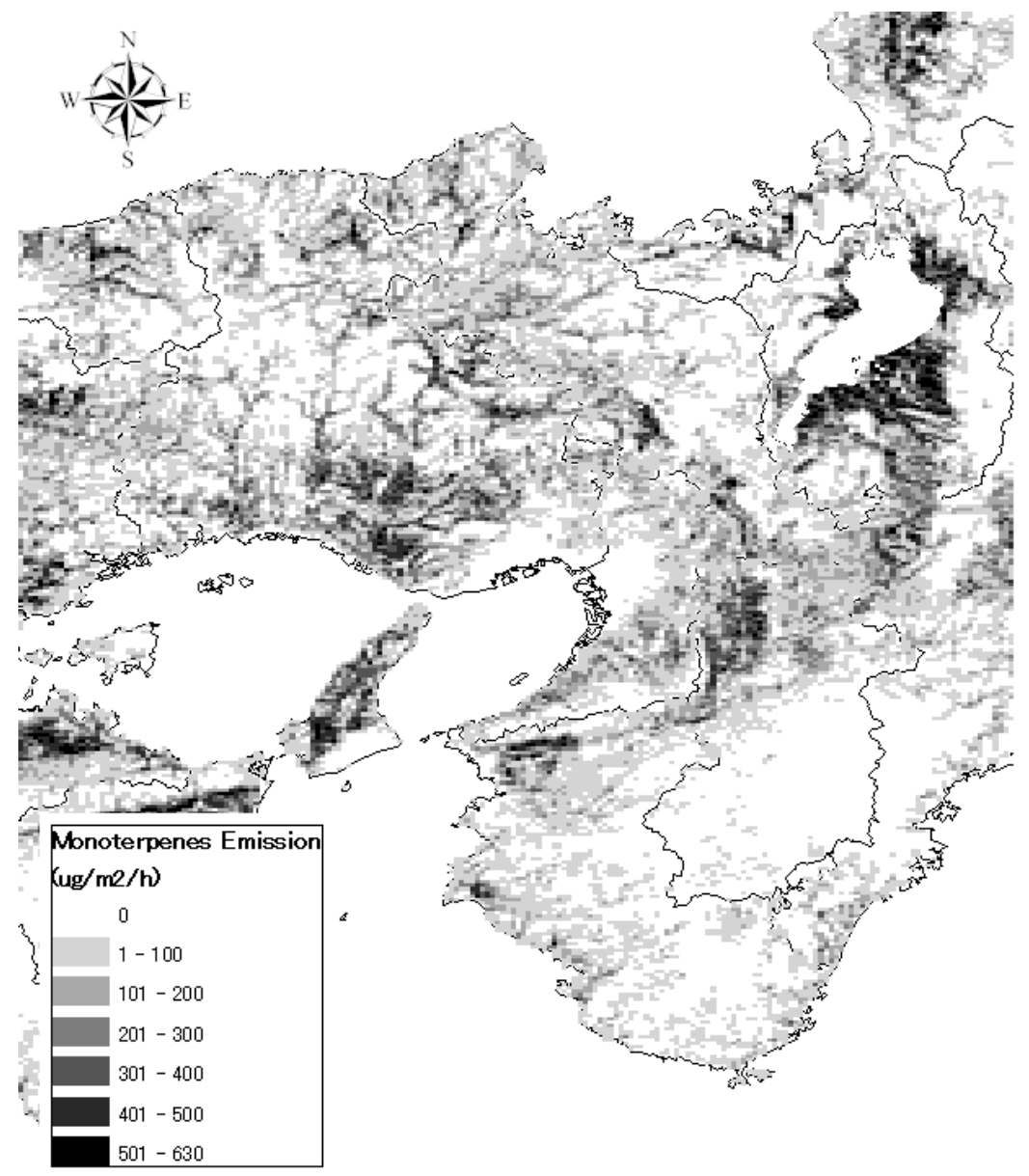

Figure 3: Emission map of monoterpene from rice plant. 


$$
C_{L}=\frac{\alpha \cdot C_{L 1} \cdot L}{\sqrt{1+\alpha^{2} \cdot L^{2}}}
$$

where $\alpha$ (0.0027), $C_{L 1}$ (1.066), $C_{T 1}(95000 \mathrm{~J} / \mathrm{mol}), C_{T 1}(230000 \mathrm{~J} / \mathrm{mol})$ and $T_{m}(314 \mathrm{~K})$ are empirical coefficients, $T_{S}$ is the standard reference temperature $(303 \mathrm{~K}), R(8.314 \mathrm{~J} / \mathrm{Kmol})$ is the universal gas constant, $T(\mathrm{~K})$ is the foliar biomass temperature and $L$ is the PAR flux $\left(\mu \mathrm{mol} / \mathrm{m}^{2} \mathrm{~s}\right)$. It was assumed that foliar temperature is equivalent to the air temperature. While isoprene emissions are coupled to the rate of biosynthesis and are therefore both temperature and PAR dependent, monoterpenes emissions from coniferous plants are mainly reported to be only temperature-dependent (Tingey [7]). Hourly monoterpene emission $E_{\text {mono }}$ were given by

$$
E_{\text {mono }}=E F_{\text {mono }} C_{T}^{m} F B D
$$

where $E F_{\text {mono }}$ is the standard monoterpene emission factor $(\mu \mathrm{g} / \mathrm{gdw} / \mathrm{h})$ and $C_{T}^{m}$ is the environmental correction factor owing to temperature defined by

$$
C_{T}^{m}=\exp \left(\beta \cdot\left(T-T_{s}\right)\right)
$$

where $\beta\left(0.09 \mathrm{~K}^{-1}\right)$ is an empirical coefficient.

Fig.4 shows the experimental isoprene emission from Quercus serrata and the equation (2). Though the experimental data varies widely, the strong dependency of temperature can be found in Fig.4. Similarly, Fig.5 shows the experimental $\alpha$-pinen from Cryptomeria japonica and the equation (5) as one of examples. Though there is only three experimental data, the dependency of temperature can be found in Fig.5. From these experimental data, we determined that we used the equation (2) and (5) in order to estimate VOCs emission in the photochemical oxidant simulation in the Kinki district.

\section{Simulation of photochemical oxidant}

\subsection{Outline of model}

The basic equations consist of momentum equations of $\mathrm{u}$ and $\mathrm{v}$ component, conservation equations of potential temperature and specific humidity, and hydrostatic equation. The vertical turbulence coefficient is determined by the turbulence closure model level 2.5. The surface flux is given by Monin-Obukhov similarity theory. The Eulerian diffusion model including the photochemical reactions (CBM IV) and the dry deposition (Resistance model) is used to calculate pollution transport. The calculated domain is the same as the region shown in Fig.1. The calculated range was set up from 13400 to 13626 of the east longitude and from 3255 to 3600 of the north latitude. The number of mesh is $33 \times 74$ and the interval of a horizontal grid is $5 \mathrm{~km}$. The interval of a vertical grid is $8 \mathrm{~m}, 8 \mathrm{~m}, 8 \mathrm{~m}, 8 \mathrm{~m}, 48 \mathrm{~m}, 129 \mathrm{~m}, 210 \mathrm{~m}, 290 \mathrm{~m}, 371 \mathrm{~m}, 452 \mathrm{~m}, 532 \mathrm{~m}, 613 \mathrm{~m}$, $694 \mathrm{~m}, 774 \mathrm{~m}$, and $855 \mathrm{~m}$ from the ground surface. 


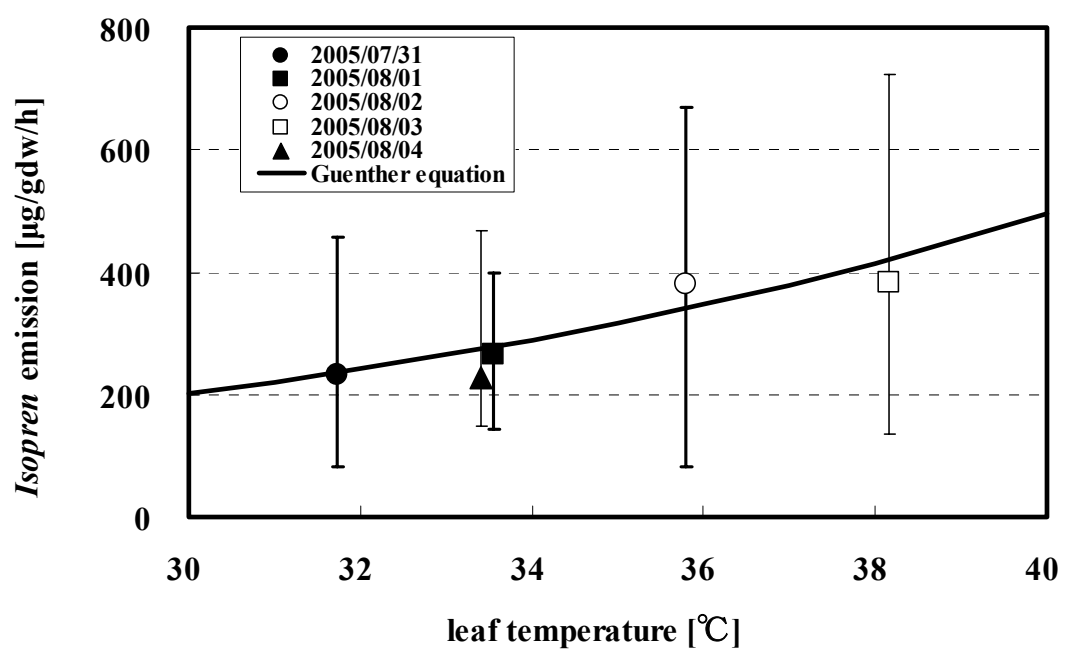

Figure 4: The experimental isoprene emission from Quercus serrata and equation (2).

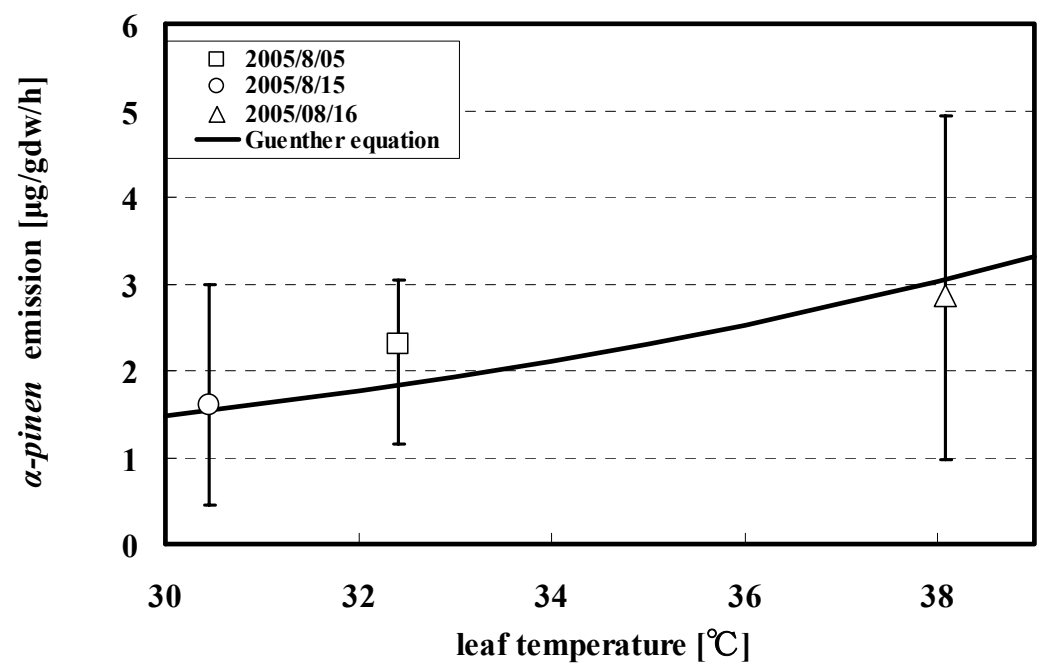

Figure 5: The experimental $\alpha$-pinen from Cryptomeria japonica and equation (5).

\subsection{Emission loads}

VOCs emission in the calculated domain varies in proportion to temperature and luminous intensity. The diurnal variation of VOCs emission from trees is shown 
in Fig.6. Since isoprene emission is strongly depended on temperature, it becomes abundant in daytime. Since isoprene isn't emitted without sunlight, it isn't emitted in nighttime. Monoterpene emission amount is around one tenth of isoprene emission amount. The natural emission amount in the calculated domain is the seven times of the anthropogenic emission amount. However the natural emission amount in the urban area including Osaka City is almost same as the anthropogenic emission amount. $\mathrm{HC} / \mathrm{NO}_{\mathrm{x}}$ ratio in the calculated domain and in the urban area is around 10 and 5, respectively.

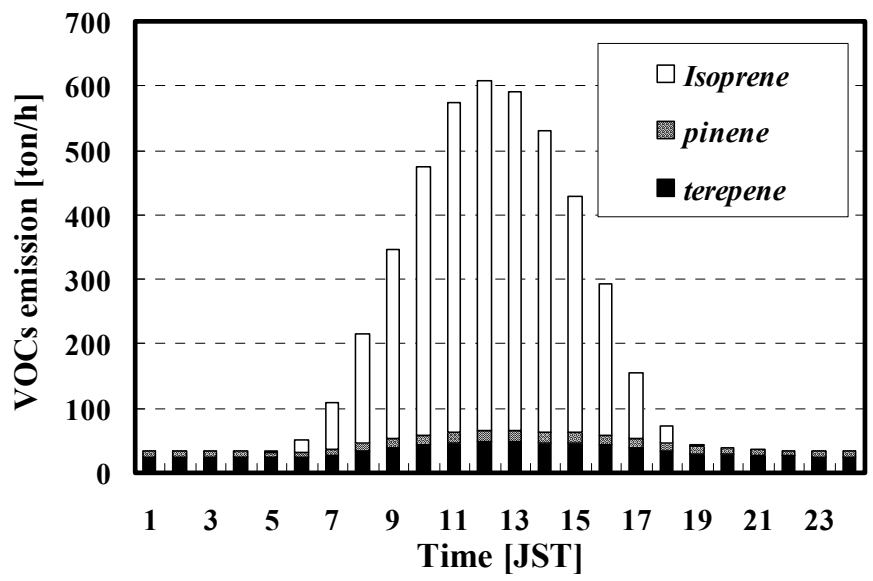

Figure 6: The diurnal variation of VOCs emission from trees.

\subsection{Simulation results}

The calculated concentrations of $\mathrm{NO}, \mathrm{NO}_{2}$ and $\mathrm{O}_{3}$ were compared with the averaged observation data in 12 places and are shown in Fig.7. The calculations of $\mathrm{NO}_{2}, \mathrm{NO}$ and $\mathrm{O}_{3}$ are a slight difference in phase, but are almost same as observed data. Simon [8] reported that the introduction of VOCs led to an increase in simulated oxidant concentrations, reaching $18-30 \%$ by the same grid of $5 \mathrm{~km} \times 5 \mathrm{~km}$ in Paris. Bao [9] reported that $0.5 \mathrm{ppb}$ to $3 \mathrm{ppb}$ increment of oxidant concentration was generated by $1^{\circ} \mathrm{C}$ temperature increment in Osaka City by the statistical analysis. With the aim of examining the influence of the increment of the temperature on the oxidant concentration, the simulation was carried out by considering of both increment of VOCs emission and the promotion of photochemical reaction due to temperature increment of $1^{\circ} \mathrm{C}$. The result is shown in Fig.8. The increment of VOCs emission has a stronger impact on the formation of oxidant than the elevation of photochemical reaction. The numerical simulation suggests that oxidant concentration increases in proportion to the increment of temperature. 


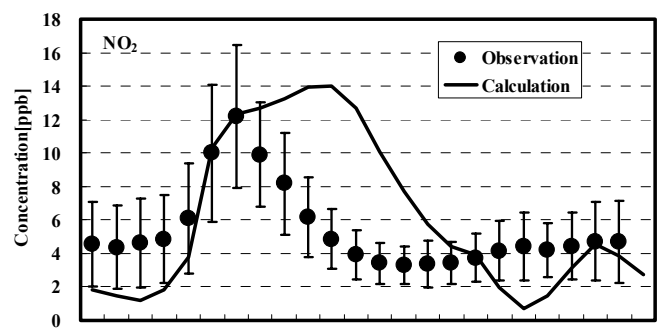

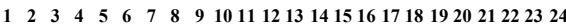
Time [JST]

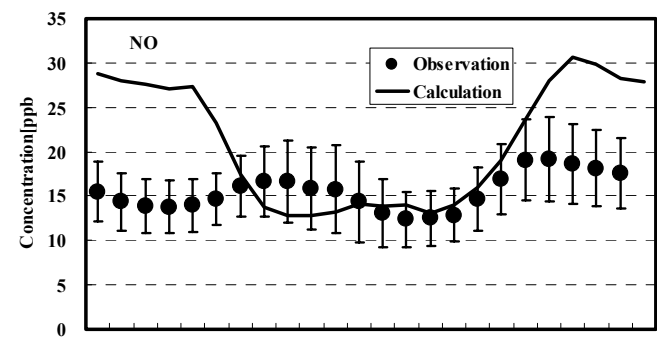

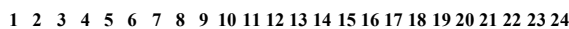
Time [JST]

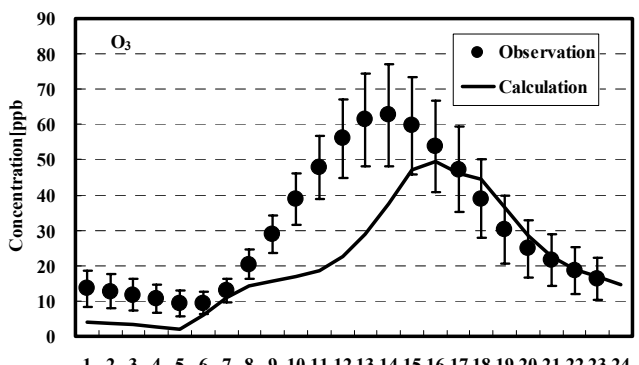
Time [JST]

Figure 7: The diurnal variation of $\mathrm{NO}_{2}, \mathrm{NO}$ and $\mathrm{O}_{3}$ concentration.

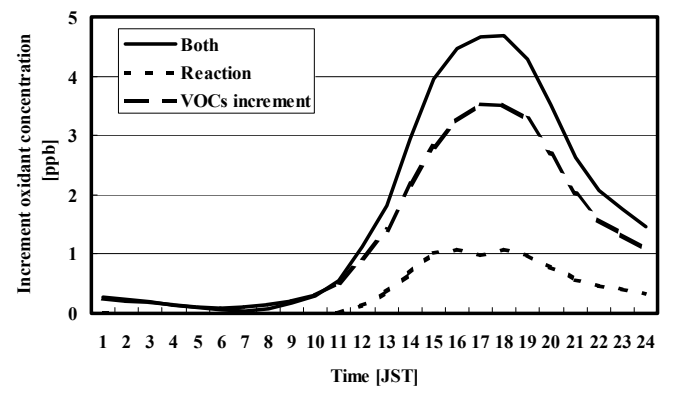

Figure 8: $\quad$ Increment of oxidant concentration due to $1^{\circ} \mathrm{C}$ increment. 


\section{References}

[1] Parra R., Science of the Total Environment, 2004 329, 241-259.

[2] Velasco E., Atmospheric Environment. 2003; 7.625-637.

[3] Wang Z., Atmospheric environment, 2003, 37 3771-3782.

[4] Xu Y, Atmospheric Environment 2002; 36, 5819 - 5829.

[5] Guenther, A., Journal of Geographical Research. 1993, 100, 8873-8892.

[6] Geron C., Atmospheric Environment, 2000, 34, 1761-1781.

[7] Tingey D., Plant Physiol., 1980, 65, 797-801.

[8] Simon V., Atmospheric Research, 2005, 74, 49-63.

[9] Bao H., Proceeding of the International Conference on Research Highlights and Vanguard Technology on Environmental Engineering in Agriculture Systems, 2005, 381-388. 